\title{
The Uses of Comparative History in Macrosocial Inquiry
}

\author{
THEDA SKOCPOL AND MARGARET SOMERS
}

\author{
Harvard University
}

Comparative history is not new. As long as people have investigated social life, there has been recurrent fascination with juxtaposing historical patterns from two or more times or places. Part of the appeal comes from the general usefulness of looking at historical trajectories in order to study social change. Indeed, practitioners of comparative history from Alexis de Tocqueville and Max Weber to Marc Bloch, Reinhard Bendix, and Barrington Moore, Jr. have typically been concerned with understanding societal dynamics and epochal transformations of cultures and social structures. Attention to historical sequences is indispensable to such understanding. Obviously, though, not all investigations of social change use explicit juxtapositions of distinct histories. We may wonder, therefore: What motivates the use of comparisons as opposed to focussing on single historical trajectories? What purposes are pursued - and how-through the specific modalities of comparative history?

Certain areas of scholarly endeavor in contemporary social science have given rise to methodological reflection even more sophisticated than the substantive applications of the methods in question, but this has certainly not been the case for comparative history. Despite the steady application of variants of this approach to macrosocial topics such as revolutions, religious evolution, political development, economic "modernization," patterns of collective violence, and the rise and fall of empires, there have been remarkably few efforts to explore the methodological aspects of comparative history as such in any systematic fashion. ${ }^{1}$ What is more, the most

An earlier version of this paper was presented at the Session on "Methods of Historical Sociology" at the Annual Meeting of the American Sociological Association, Boston, Massachusetts, August 1979. Thanks go to Bill Skocpol for helping us create the figures in the paper. We are also indebted for comments to Gary Hamilton, Michael Hechter, Lynn A. Hunt, Bruce Johnson, Barbara Laslett, Dietrich Rueschemeyer, and Gilbert Shapiro. The insights of their comments frequently outran our ability to make use of them in moderate revisions; consequently we alone are responsible for the arguments presented here.

\footnotetext{
'Existing literature on "comparative methods" in sociology has tended either to focus heavily on macrosociological theories and theorists or to emphasize issues of conceptualiza0010-4175/80/2309-0500\$2.00 (C) 1980 Society for Comparative Study of Society and History
} 
notable recent discussions by Sewell, Lijphart, and Smelser have all mistakenly tried to collapse distinct types of comparative history into a single methodological logic. ${ }^{2}$ This logic is seen as analogous in all important respects to the mode of hypothesis-testing through multivariate analysis that characterizes those areas of the social sciences where statistical or experimental research designs prevail. ${ }^{3}$

Notwithstanding such attempts at homogenization, there are, in fact, at least three distinct logics-in-use of comparative history. One of them, which we shall label comparative history as macro-causal analysis, actually does resemble multivariate hypothesis-testing. But in addition there are two other major types: comparative history as the parallel demonstration of theory; and comparative history as the contrast of contexts. Each of the three major types of comparative history assigns a distinctive purpose to the juxtaposition of historical cases. Concomitantly, each has its own requisites of case selection, its own patterns of presentation of arguments, and-perhaps most important-its own strengths and limitations as a tool of research in macrosocial inquiry.

The three major logics have enough individual integrity that prototypical recent works of comparative history can be identified as primarily embodying one logic or another ${ }^{4}$ We propose to introduce the major types and reflect upon their characteristics by using as our initial examples comparative-historical works that rely primarily upon a single logic. In order to underline that each major methodological logic is compatible with

tion and measurement as these especially affect cross-cultural surveys and field research. The former tendency is exemplified by Robert M. Marsh, Comparative Sociology: A Codification of Cross-Societal Analysis (New York: Harcourt, Brace and World, 1967); and Ivan Vallier, ed., Comparative Methods in Sociology: Essays on Trends and Applications (Berkeley and Los Angeles: University of California Press, 1971). The latter tendency is exemplified by Donald P. Warwick and Samuel Osherson, eds., Comparatice Research Methods (Englewood Cliffs, N.J.: Prentice-Hall, 1973).

2 William H. Sewell, Jr., "Marc Bloch and the Logic of Comparative History," History and Theory 6(2) (1967):208-18; Arend Lijphart, "Comparative Politics and the Comparative Method," American Political Science Review 65(3-4) (1971): 682-93; and Neil J. Smelser, Comparative Methods in the Social Sciences (Englewood Cliffs, N.J.: Prentice-Hall, 1976).

${ }^{3}$ This tendency to collapse all comparative history into multivariate analysis has occurred despite the fact that both Max Weber (whose work is extensively surveyed by Smelser) and Marc Bloch (whose methodological views form the basis for Sewell's article) recognized that comparative history could be used not only for hypothesis testing, but also to contrast different societies or cultures and to highlight their respective individual features. Max Weber should be considered a prime practitioner among classical sociologists of the type of comparative history that we will label "Contrast-oriented" and discuss at length below. For Marc Bloch's views on comparative history, see his "A Contribution towards a Comparative History of European Societies," in Land and Work in Medieval Europe: Selected Papers by Marc Bloch, trans., J.E. Anderson (New York: Harper and Row, 1967): 44-81.

${ }^{4}$ To be sure, the major logics of comparative history are sometimes combined in scholarly works. Later in this paper we will show that well-known recent books by Perry Anderson and Charles, Louise, and Richard Tilly combine different possible pairs of the major types of comparative history. 
disparate theoretical perspectives and subject matters, we shall use several different studies, varying in these respects, to exemplify each major type of comparative history. As we proceed the reader should bear in mind that in no case will we present full methodological dissections of the works we use as illustrations. For example, many crucial issues about the role of theories and concepts in relation to historical evidence will necessarily be skirted. Our purpose here is strictly to discuss the uses in macrosocial research of comparisons across historical trajectories, and the ways in which such uses influence research designs and the presentation of arguments in scholarly publications.

COMPARATIVE HISTORY AS THE PARALLEL DEMONSTRATION OF THEORY

In this first type of comparative history, the reason for juxtaposing case histories is to persuade the reader that a given, explicitly delineated hypothesis or theory can repeatedly demonstrate its fruitfulness-its ability convincingly to order the evidence--when applied to a series of relevant historical trajectories.

Despite considerable differences of subject-matter and theoretical approach, both S. N. Eisenstadt's The Political Systems of Empires and Jeffery M. Paige's Agrarian Revolution use comparative history in this way. ${ }^{5}$ These books intend above all to convince their readers of the validity of certain theoretical arguments: a structure-functionalist theory of the emergence, persistence, and decline of "centralized historical bureaucratic empires" in the case of Eisenstadt's Political Systems; an economic-determinist theory of rural class relations and the potential political behavior of cultivating and noncultivating classes in the case of Paige's Agrarian Revolution. The primary mode of demonstrating the theory is something other than comparative history in both books. Eisenstadt relies chiefly upon conceptual elaboration and deduction from structure-functionalist premises; Paige spends the first third of Agrarian Revolution presenting a logically elegant theoretical model of four types of rural class conflict and a statistical demonstration of its fruitfulness when applied to cross-sectional data on 135 agricultural export sectors in 70 underdeveloped countries. Nevertheless, in both Eisenstadt's and Paige's books, comparative history serves as an ancillary mode of theoretical demonstration. Historical instances are juxtaposed to demonstrate that the theoretical arguments apply convincingly to multiple cases that ought to fit if the theory in question is indeed valid. Cases are selected to cover all possibilities, or to represent a range of sub-types or points on continua. The point of the comparison is to

${ }^{5}$ S. N. Eisenstadt, The Political Systems of Empires: The Rise and Fall of Historical Bureaucratic Societies (New York: Free Press, 1963); and Jeffery M. Paige, Agrarian Revolution: Social Movements and Export Agriculture in the Underdeveloped World (New York: Free Press, 1975). 
assert a similarity among the cases-similarity, that is, in terms of the common applicability of the overall theoretical arguments that Eisenstadt and Paige are respectively presenting.

The last two-thirds of Jeffery Paige's Agrarian Revolution is devoted to in-depth analyses of agrarian class relations and politics in three thirdworld countries: Peru, Angola, and Vietnam. The broad applicability of Paige's theory is sweepingly demonstrated in this exploration of case histories from Latin America, Africa, and Asia. More interesting still, the three countries Paige discusses serve to illustrate concretely most of the major sub-parts of his overall model of rural class conflict: Peru provides examples of agrarian revolts emerging from commercial haciendas and of reform labor movements on plantations; Angola illustrates the connection of a nationalist revolutionary movement to migratory labor estates; and Vietnam shows to Paige's satisfaction that socialist revolution emerges from a sharecropping agricultural system. Taken together, therefore, Paige's case histories not only repeatedly demonstrate the applicability of his theory, they also enrich his presentation of the alternative possible forms of sociopolitical conflict that the theory is meant to predict and explain.

In The Political Systems of Empires, S. N. Eisenstadt repeatedly juxtaposes slices of very diverse historical cases: the ancient empires of Egypt, Babylon, the Incas and the Aztecs; the Chinese Empire; the Persian empires; the Roman and Hellenic empires; the Byzantine empires; certain Hindu states; the Arab caliphate, Arab Moslem states and the Ottoman empire; and various European states and overseas empires. Rhetorically Eisenstadt asks: "Are we justified in grouping these various historically and geographically separate and distinct, societies under one heading, and claiming that they constitute or belong to one type?" "To some extent," Eisenstadt answers, "this whole work will continuously have to substantiate this claim." Indeed, as Political Systems proceeds, Eisenstadt alternates back and forth between laying out his theoretical argument and illustrating each part's parallel applicability to aspects of case histories selected from the range of empires included in his type "centralized historical bureaucratic empires" as a whole. ${ }^{7}$ It is characteristic of all works of Parallel comparative history to elaborate theoretical models and hypotheses before turning to historical case illustrations. Yet whereas Paige does all of his theorizing before discussing the case histories, Eisenstadt develops

\footnotetext{
${ }^{6}$ Eisenstadt, Political Systems, p. 12.

${ }^{7}$ Although Parallel comparative history is Eisenstadt's predominant strategy in Political Systems, he also does a bit of causal analysis using an approximation to controlled comparison. Specifically Eisenstadt uses Macro-analytic comparative history when he argues (pp. 106-7) that some societies had one, but not both, necessary conditions to become bureaucratic empires, contrasting these "failed" cases to "successful" ones.
} 
his theory in stages and divides historical cases into bits and pieces relevant to each theoretical aspect as he presents it. Much more apparently than in Paige's book, therefore, the historical cases in Political Systems function strictly to substantiate the completeness of coverage and the consistent applicability of Eisenstadt's theoretical approach. ${ }^{8}$

\section{COMPARATIVE HISTORY AS THE CONTRAST OF CONTEXTS}

A second major type of comparative history pursues through the juxtaposition of cases an almost exactly opposite objective from that of Parallel comparative history. The Parallel comparativists seek above all to demonstrate that a theory similarly holds good from case to case; for them differences among the cases are primarily contextual particularities against which to highlight the generality of the processes with which their theories are basically concerned. But scholars such as Clifford Geertz in Islam Observed, James Lang in Conquest and Commerce, and Reinhard Bendix in Nation-Building and Citizenship and Kings or People make use of comparative history to bring out the unique features of each particular case included in their discussions, and to show how these unique features affect the working-out of putatively general social processes. ${ }^{9}$ A bove all, contrasts are drawn between or among individual cases. Usually such contrasts are developed with the aid of references to broad themes or orienting questions or ideal-type concepts. Themes and questions may serve as frameworks for pointing out differences between or among cases. Ideal types may be used as sensitizing devices-- benchmarks against which to establish the particular features of each case. Themes, questions, or ideal types may be posed explicitly at the start; or they may be allowed to "emerge" as the historical discussions proceed. Whereas explicit theorizing is characteristic of the Parallel type of comparative history, what matters more in the Contrastoriented type is that the historical integrity of each case as a whole is carefully respected. For much of the thrust of this variant of comparative history is to suggest that particular nations, empires, civilizations, or religions constitute relatively irreducible wholes, each a complex and unique sociohistorical configuration in its own right.

Books based upon straightforward paired comparisons nicely illustrate the basic essence of Contrast-oriented comparative history. Clifford Geertz's lovely Islam Observed is, as its subtitle tells us, about "religious

\footnotetext{
${ }^{8}$ An interesting by-product of Paige's willingness to present detailed, integral case accounts (as opposed to Eisenstadt's scattered fragments) is that a reader skeptical of Paige's theory finds it relatively easy (unlike a reader skeptical of Eisenstadt's theory) to use the historical cases to criticize Paige's theory and to tease out alternative explanations. See, for example, Margaret R. Somers and Walter L. Goldfrank, "The Limits of Agronomic Determinism: A Critique of Paige's Agrarian Revolution," Comparative Studies in Society and History 21(3) (July 1979): 443-58.

${ }^{y}$ Full references will be given below as each book is individually discussed or cited.
} 
development in Morocco and Indonesia." ${ }^{10}$ Geertz wonders what happens in the "modernizing" countries when "established connections between particular varieties of faith and the cluster of images and institutions which have classically nourished them are for certain people in certain circumstances coming unstuck." "General answers Geertz finds "not very enlightening" and so he turns to comparative (anthropological) history hoping "to stumble upon general truths while sorting through special cases." 12 In a first chapter tellingly entitled "Two Countries, Two Cultures," Geertz informs us why he finds it fruitful to compare Indonesia and Morocco:

Their most obvious likeness is . . their religious affiliation; but it is also, culturally speaking at least, their most obvious unlikeness. They stand at the eastern and western extremities of the narrow band of classical Islamic civilization which, rising in Arabia, reached out along the midline of the Old World to connect them, and, so located, they have participated in the history of that civilization in quite different ways, to quite different degrees, and with quite different results. They both incline toward Mecca, but, the antipodes of the Muslim world, they bow in different directions. ${ }^{13}$

For Geertz, therefore, Indonesia and Morocco are so promising to compare precisely because, through the sharp contrast they offer within Islam, "they form a kind of commentary on one another's character." 14 As Geertz's choice of cases suggests, the task of the Contrast-oriented comparative historian is facilitated when maximally different cases within given bounds are chosen for comparison. Parallel comparative historians seek broad coverage in their selection of cases; Contrast-oriented comparativists may seek this too, but clear-cut differences between or among cases are more important.

James Lang in Conquest and Commerce is less explicit than Geertz in justifying the historical comparison he chooses to make, yet in this work as well two cases offer through systematic contrasts a commentary on each other's uniquenesses. ${ }^{15}$ Lang is interested in exploring the dissimilar societies that Europeans of different national origins built in the New World. To understand the factors that shaped and perpetuated key differences-from the establishment of colonial empires through to their dismantling by American independence movements - Lang chooses to juxtapose the histories of "Spain and England in the Americas." (Notice that the choice is not England and France, or France and Spain, but instead the pair

${ }^{10}$ Clifford Geertz, Islam Observed: Religious Development in Morocco and Indonesia (Chicago: University of Chicago Press, 1971).

11 Ibid., p. 3

12 Ibid., p. 4

${ }^{13}$ Ibid.

${ }^{14} \mathrm{Ibid}$.

15 James Lang, Conquest and Commerce: Spain and England in the Americas (New York: Academic Press, 1975). 
that maximizes the contrast between bureaucratic and commercial contexts.) Lang asks a series of common analytic questions about the historical experiences of English and Spanish America. Indeed, for a reader inspired by the urge to formulate potentially generalizable causal hypotheses, there are many possibilities implicit in Lang's analytic questions. But Lang himself does not pursue these possibilities. For him it is enough to let the questions "reveal dramatically different answers for the two colonial situations." 16

To see the rationale behind this concern with contrasts that characterizes practitioners of our second major type of comparative history, we can do no better than to turn to Reinhard Bendix. No contemporary scholar has done more to explicate, as well as to apply, the logic of this variant of comparative history. As Bendix put it in an article meant to introduce his newest book, Kings or People:

By means of comparative analysis I want to preserve a sense of historical particularity as far as I can, while still comparing different countries. Rather than aim at broader generalizations and lose that sense, $I$ ask the same or at least similar questions of divergent materials and so leave room for divergent answers. I want to make more transparent the divergence among structures of authority and among the ways in which societies have responded to the challenges implicit in the civilizational accomplishments of other countries. ${ }^{17}$

Bendix's stress here upon making divergences "more transparent" echoes a related argument he made in the Introduction to Nation-Building and Citizenship:

Comparative sociological studies ... increase the "visibility" of one structure by contrasting it with another. Thus, European feudalism can be more sharply defined by comparison, say, with Japanese feudalism, the significance of the Church in Western civilization can be seen more clearly by contrast with civilizations in which a comparable clerical organization did not develop. ${ }^{18}$

Both of Reinhard Bendix's major comparative studies of societal patterns of authority, Nation-Building and Citizenship and Kings or People, practice the variant of comparative history that he advocates. ${ }^{19}$ In each work, general "issues" and "themes" are set out at the beginning (of the book as a whole and at the beginning of each major section). Although to the dissenting eyes of (say) a Marxist or a capitalist world-system theorist, such introductory statements look very much like a full-fledged theory of political development (synthesized from Tocqueville, Hintze, and Weber),

\footnotetext{
16 Ibid., dust jacket.

${ }^{17}$ Reinhard Bendix, "The Mandate to Rule: An Introduction," Social Forces 55(2) (December 1976), p. 247.

${ }^{18}$ Reinhard Bendix, Nation-Building and Citizenship (new enlarged ed.) (Berkeley and Los Angeles: University of California Press, 1977; orig. 1964), pp. 16-17.

19 Ihid:; and Reinhard Bendix, Kings or People: Power and the Mandate to Rule (Berkeley and Los Angeles: University of California Press, 1978).
} 
Bendix does not present his ideas as an explanation to be tested or applied. Rather he sees them as either "sociological universals" or middle-range ideal types meant to establish a frame of reference for the historical case accounts and comparisons between and among them. In turn, the comparisons reveal the particularities of the cases. In Nation-Building, forms of "political modernization" in Western Europe are contrasted to analogous changes (or their absence) in Russia, Japan, and India. And in Kings or People, England, France, Imperial Germany and Prussia, Russia, and Japan are discussed in depth and comparatively to show that, although these countries have all experienced epochal transformations in patterns of political legitimation, "[a]uthority in the name of the people has proved as varied in practice as the authority of kings" (emphasis added). ${ }^{20}$

Bendix cogently sums up the ambitions and self-imposed limitations - of the Contrast-oriented type of comparative history:

Comparative analysis should sharpen our understanding of the contexts in which more detailed causal inferences can be drawn. Without a knowledge of contexts, causal inference may pretend to a level of generality to which it is not entitled. On the other hand, comparative studies should not attempt to replace causal analysis, because they can only deal with a few cases and cannot easily isolate the variables (as causal analysis must). ${ }^{21}$

In short, Contrast-oriented comparativists aim to place historical limits on overly generalized theories, but they do not aspire to generate new explanatory generalizations through comparative historical analysis.

\section{COMPARATIVE HISTORY AS MACRO-CAUSAL ANALYSIS}

Notwithstanding Bendix's strictures, a third group of scholars in fact uses comparative history primarily for the purpose of making causal inferences about macro-level structures and processes. Included here are Barrington Moore, Jr., in Social Origins of Dictatorship and Democracy; Theda Skocpol in States and Social Revolutions; Frances V. Moulder in Japan, China and the Modern World Economy; Robert Brenner in "Agrarian Class Structure and Economic Development in Pre-Industrial Europe"; and Gary G. Hamilton in "Chinese Consumption of Foreign Commodities: A Comparative Perspective." 22

Barrington Moore, Jr., the dean of contemporary practitioners of Macro-analytic comparative history, provides a rationale for this approach in the Preface to Social Origins:

In the effort to understand the history of a specific country a comparative perspective can lead to asking very useful and sometimes new questions. ... Comparisons can serve as a rough negative check on accepted historical explanations. And a

${ }^{20}$ Bendix, Kings or People, p. 5.

${ }^{21} \mathrm{lbid}$., p. 15.

22 Full references will be given below as each work is individually discussed or cited. 
comparative approach may lead to new historical generalizations. In practice these features constitute a single intellectual process and make such a study more than a disparate collection of interesting cases. For example, after noticing that Indian peasants have suffered in a material way just about as much as Chinese peasants during the nineteenth and twentieth centuries without generating a massive revolutionary movement, one begins to wonder about traditional explanations of what took place in both societies and becomes alert to factors affecting peasant outbreaks in other countries, in the hope of discerning general causes. Or after learning about the disastrous consequences for democracy of a coalition between agrarian and industrial elites in nineteenth- and early twentieth-century Germany, the much discussed marriage of iron and rye- one wonders why a similar marriage between iron and cotton did not prevent the coming of the Civil War in the United States; and so one has taken a step toward specifying configurations favorable and unfavorable to the establishment of modern Western democracy (emphases added). ${ }^{23}$

One notices in Moore's Preface to Social Origins much the same suspicion of overly generalized theories that characterizes the work of Reinhard Bendix. As Moore puts it, "too strong a devotion to theory always carries the danger that one may overemphasize the facts that fit a theory beyond their importance in the history of individual countries." 24 "That comparative analysis is no substitute for detailed investigation of specific cases is obvious," Moore declares. ${ }^{25}$ Yet it is equally apparent that Moore cares much more than Bendix about using historical comparisons to test the validity of existing theoretical hypotheses and to develop new causal generalizations to replace invalidated ones. The flavor of the intellectual operation involved is effectively conveyed in the above quote. Rather than exploring and contrasting whole histories in terms of pre-given themes, as the Contrast-oriented comparativists do, Macro-analysts like Moore tend to move back and forth between alternative explanatory hypotheses and comparisons of relevant aspects of the histories of two or more cases. As Moore notes, Macro-analysts thus try to specify "configurations favorable and unfavorable" to particular outcomes they are trying to explain.

The logic involved in the use of comparative history for Macro-causal analysis resembles that of statistical analysis, which manipulates groups of cases to control sources of variation in order to make causal inferences when quantitative data are available about a large number of cases. This third variant of comparative history is, indeed, a kind of multivariate analysis to which scholars turn in order to validate causal statements about macro-phenomena for which, inherently, there are too many variables and not enough cases. Macro-analytic comparative historians proceed by selecting or referring to aspects of historical cases in order to set up approximations to controlled comparisons. Always this is done in relation

${ }^{23}$ Barrington Moore, Jr., Social Origins of Dictatorship and Democracy: Lord and Peasant in the Making of the Modern World (Boston: Beacon Press, 1966), pp. xiii-xiv.

${ }^{24}$ Ibid., p. xiii.

${ }^{25}$ Ibid., p. xiv. 
to particular explanatory problems and (one or more) hypotheses about likely causes.

Logically speaking, Macro-analysts proceed according to one of two basic analytic designs, or a combination of these. On the one hand, Macro-analysts can try to establish that several cases having in common the phenomenon to be explained also have in common the hypothesized causal factors, although the cases vary in other ways that might have seemed causally relevant. This approach was once labelled by John Stuart Mill the "Method of Agreement." ${ }^{26}$ On the other hand, Macro-analysts can contrast cases in which the phenomenon to be explained and the hypothesized causes are present to other ("negative") cases in which the phenomenon and the causes are both absent, although they are as similar as possible to the "positive" cases in other respects. This procedure Mill called the "Method of Difference." 27 Taken alone, this second approach is more powerful for establishing valid causal associations than is the "Method of Agreement." Sometimes, however, it is possible to combine the two methods by using at once several positive cases along with suitable negative cases as contrasts.

A monumental work of comparative history, Barrington Moore's Social Origins of Dictatorship and Democracy primarily uses Mill's Method of Agreement, yet it also argues at times along the lines of the Method of Difference. Social Origins identifies three alternative political routes to the modern world: (1) through "bourgeois revolution" to liberal democracy; (2) through "revolution from above" to fascism, and (3) through "peasant revolution" to communism. With the aid of causal variables referring to strengths of bourgeoisies in relation to landlords, to modes of agricultural commercialization, and to types of peasant communities and peasant/ landlord relations, Moore seeks to explain why specified sets of major countries have travelled one route rather than the others. ${ }^{28}$ Within each of his routes, Moore primarily argues along the lines of the Method of Agreement. Each route has two or three nations about whose historical development Moore makes a common causal argument, at times using the

26 John Stuart Mill, "Two Methods of Comparison" (excerpt from A System of Logic, 1888), in Amatai Etzioni and Frederic L. Du Bow, eds., Comparative Perspectives: Theories and Methods (Boston: Little, Brown, 1970), p. 206.

27 Ibid., pp. 207-10.

${ }^{28}$ For a summary of the variables, see the table in Theda Skocpol, "A Critical Review of Barrington Moore's 'Social Origins of Dictatorship and Democracy,", Politics and Society 4(3) (Fall 1973), p. 10. Insofar as Moore does any of our major kinds of comparative history in Social Origins, he uses the Macro-analytic approach. However, it is worth noting that much of Social Origins is intended by Moore as straightforward historical analysis of causal sequences specific to the individual countries. As he puts it in the Preface (p. xiii), "the analysis of the transformation of agrarian society in specific countries produces results at least as rewarding as larger generalizations... [F]or any given country one is bound to find lines of causation that do not fit easily into more general theories." 

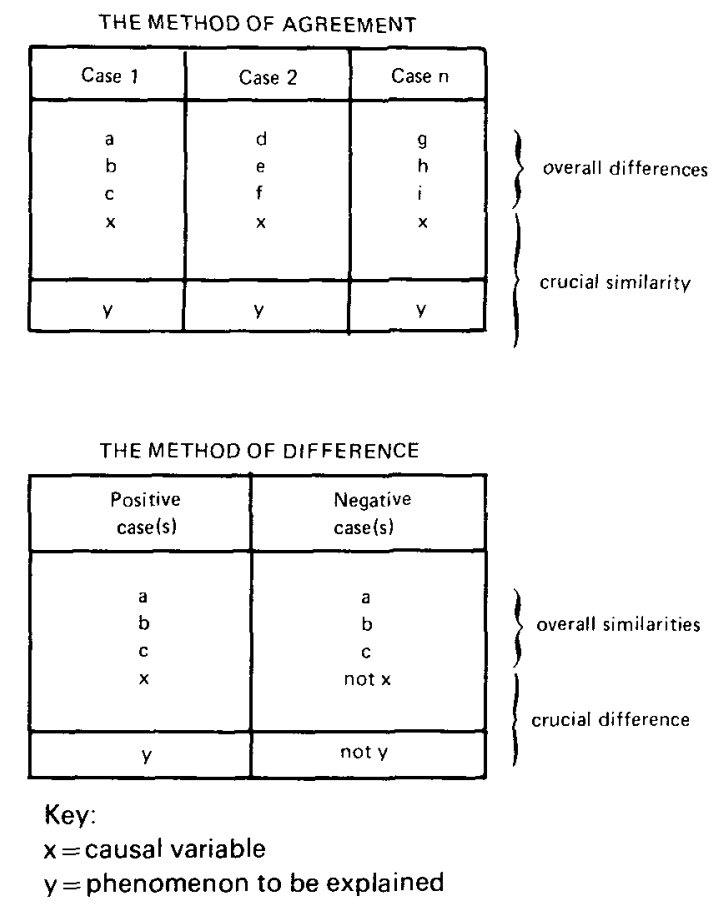

Figure 1. Two Designs for Macro-Analytic Comparative History (from John Stuart Mill)

differences of the cases to eliminate possible alternative arguments. Simultaneously, at the level of comparisons across his three major routes, Moore makes some use of the Method of Difference; for as he discusses each particular route, Moore occasionally refers to one or both of the other two routes, using their contrasting developmental patterns to help validate the causal arguments being made for the other route in question. Not only in terms of its substantive scope, therefore, but also in terms of the complexity of its explanatory design, Social Origins is a work of virtually unparalleled ambition.

Theda Skocpol's States and Social Revolutions is much less ambitious. ${ }^{29}$ Yet, especially in its first part on "The Causes of Social Revolutions in France, Russia, and China," it too employs a combination of Mill's analytic approaches, although with more explicit emphasis upon the Method of Difference. Skocpol argues that, despite differences along many dimensions that many theorists of revolution would consider decisive, Bourbon France in the late eighteenth century, late Imperial China after

${ }^{29}$ Theda Skocpol, States and Social Revolutions: A Comparative Analysis of France, Russia, and China (Cambridge and New York: Cambridge University Press, 1979). 
1911, and Tsarist Russia from March 1917, all experienced social revolutionary crises for similar analytic reasons. By stressing the causal similarities in the face of other potentially important differences, Skocpol makes use of the Method of Agreement. Yet she also proceeds according to the Method of Difference by introducing analytically focussed contrasts between France, Russia, and China, on the one hand, and selected parts of the histories of England, Prussia/Germany, and Japan, on the other. These are suitable controls, Skocpol argues, because they are countries that did not undergo successful social-revolutionary transformations even though they were similar in many ways (structurally and historically) to France, Russia, and China. Skocpol uses contrasts to various sets of countries (in various periods of their histories) to validate different specific parts of her causal arguments about France, Russia, and China. For arguments about crises in states as one cause of social-revolutionary crises, she makes contrasts to the Japanese Meiji Restoration and the Prussian Reform Movement; and for arguments about agrarian structures and peasant revolts in revolutions, she makes contrasts to the English Parliamentary Revolution and the (failed) German revolution of 1848-50. In Skocpol's States and Social Revolutions only the "positive" cases of social revolution receive extensive discussion. "Negative"-or control-cases are discussed much less fully. For they are introduced strictly for the purpose of helping to validate the main argument about the causes of social revolutions in France, Russia, and China.

As a straightforward comparison of two countries, Frances Moulder's Japan, China and the Modern World Economy exemplifies the Method of Difference in action in yet another way. ${ }^{30}$ Moulder's explanatory objective is to show that Japan's early, successful breakthrough to modern industrialization, in contrast to China's prolonged stagnation (from the mid-nineteenth to the mid-twentieth centuries), should be attributed not to differences between the cultural traditions or domestic economies of the two countries, but rather to the fewer constraints placed upon Japanese development by Western imperialist intrusions. ${ }^{31}$ In order to substantiate

${ }^{30}$ Frances V. Moulder, Japan. China and the Modern World Economy: Toward a Reinterpretation of East Asian Detelopment ca. 1600 to ca. 1918. (Cambridge and New York: Cambridge University Press, 1977).

${ }^{31}$ Moulder's book derives its central hypotheses from Immanuel Wallerstein's theory of the capitalist world-economy. For the basic tenets of this theory, see: Immanuel Wallerstein, "The Rise and Future Demise of the World-Capitalist System: Concepts for Comparative Analysis," Comparative Studies in Society and History 16(4) (September 1974): 387-415; and Immanuel Wallerstein, The Modern World-System: Capitalist Agriculture and the Origins of the European World-Economy in the Sixteenth Century (New York: Academic Press, 1974). The theory of the capitalist world-system has been used in conjunction with at least two of the logics of comparative history: Wallerstein himself uses the Parallel approach to show that his overall world-system model can account for the histories of countries in the "core," "semi- 
her causal argument as opposed to alternatives that emphasize domestic differences between Japan and China, Moulder must establish the similarity in all apparently causally relevant aspects of the domestic structures of Tokugawa Japan and late Imperial China. And she must also show that Japan and China differed (in the appropriate direction and at the relevant times) in terms of the Western intrusions to which they were subjected. Indeed, Moulder's entire book is a closely argued attempt to establish exactly this pattern of many overall similarities and the one crucial difference between Japan and China, its logic being an impeccable application of the Method of Difference.

Like Skocpol's and Moulder's books, two tightly argued articles by Robert Brenner and Gary Hamilton respectively use the Method of Difference to support key explanatory arguments. ${ }^{32}$ Even more than the Skocpol and Moulder books, moreover, these articles employ comparative history to refute alternative, competing arguments about their primary concerns. Robert Brenner's article on "Agrarian Class Structure and Economic Development..." seeks to explain long-term economic change in late medieval and early modern Europe, in particular "the intensification of serfdom in Eastern Europe in relation to its process of decline in the West" and "the rise of agrarian capitalism and the growth of agricultural productivity in England in relation to their failure in France. ${ }^{33}$ Determined to debunk explanations of European economic growth that attribute causal significance to market expansion or to demographic trends, Brenner undermines such arguments by showing that the same putatively causal processes produced different outcomes in different parts of Europe (especially between Eastern and Western Europe, but also between regions of each of these zones). Then Brenner proceeds to argue that variables referring to class relations and the strength of peasant communities versus landlords can better account for the variations in economic development he wants to explain.

In his article on "Chinese Consumption of Foreign Commodities," Gary Hamilton is concerned with what factors influence the non-Western use of Western commodities. The unwillingness of the nineteenth-century

periphery," "periphery," and "external" arenas. And Moulder's book shows that Wallerstein's theory is also compatible with a Macro-analytic approach. True, there is only one world-economy. But there need not be only one unit of analysis, insofar as causal hypotheses about developments in nations, regions, cross-sections of "world time," etc., can be formulated with the guidance of the theory. Approximations to controlled comparisons may then be possible to test such hypotheses, as Moulder's comparison of Japan and China demonstrates.

32 Robert Brenner, "Agrarian Class Structure and Economic Development in Pre-Industrial Europe," Past and Present no. 70 (February 1976): 30-75; and Gary G. Hamilton, "Chinese Consumption of Foreign Commodities: A Comparative Perspective," American Sociological Review 42(6) (December 1977): 877-91.

33 Brenner, "Agrarian Class Structure," p. 47. 
Chinese to buy very many Western textile products provides a particularly intriguing problem for analysis. Why this Chinese reluctance? Hamilton outlines at the outset three alternative lines of explanation: faulty marketing and merchandizing arguments, cultural explanations, and a Weberian "status-competition" hypothesis. Methodically, Hamilton makes ingenious use of historical comparisons across space and time to dispose of the first two explanations. He shows that the economic arguments cannot explain why China differed from other non-Western countries in the nineteenth century, and he argues that a Confucian-culture explanation cannot explain why Chinese in earlier historical periods were willing to consume foreign products. Finally, Hamilton introduces his preferred status-competition explanation and demonstrates that it can explain the cross-national and cross-temporal variations that its competitors could not. All in all Hamilton is able to make optimally effective use of comparative history as a tool of causal analysis, especially because he ranges freely across cultures and historical epochs in order to find the logically necessary comparisons to further his explanatory argument.

THE TRIANGLE OF COMPARATIVE HISTORY AND SOME WORKS THAT COMBINE LOGICS

Parallel comparative history, Contrast-oriented comparative history, and Macro-analytic comparative history are, therefore, three distinct approaches that actually have been used by historical comparativists. For each of these major types of comparative history, we have reviewed examples of published works that clearly, and virtually exclusively, embody only one of these logics.

Yet it is important to recognize that works of comparative history sometimes combine (especially in pairs) the major logics we have reviewed. Two notable, recently published comparative historical studies that do in fact combine logics are Lineages of the Absolutist State by Perry Anderson and The Rebellious Century 1830-1930 by Charles, Louise, and Richard Tilly ${ }^{34}$ As indicated in Figure 2, these works can be located at midpoints on dimensions shared by pairs of the major logics of comparative history.

A discussion of each of the dimensions of the "Triangle of Comparative History" in Figure 2 can help to further clarify the features of the major types of comparative history, as well as the characteristics and likely incidence of works that mix the various possible pairs of types.

To begin with dimension (a) of the Triangle: the Parallel and Contrastoriented types of comparative history share the feature that prior general ideas--theories in the case of the Parallel approach; themes or questions in

${ }^{34}$ Perry Anderson, Lineages of the Absolutist State (London: New Left Books, 1974); and Charles Tilly, Louise Tilly, and Richard Tilly, The Rebellious Century, 1830-1930 (Cambridge: Harvard University Press, 1975). 


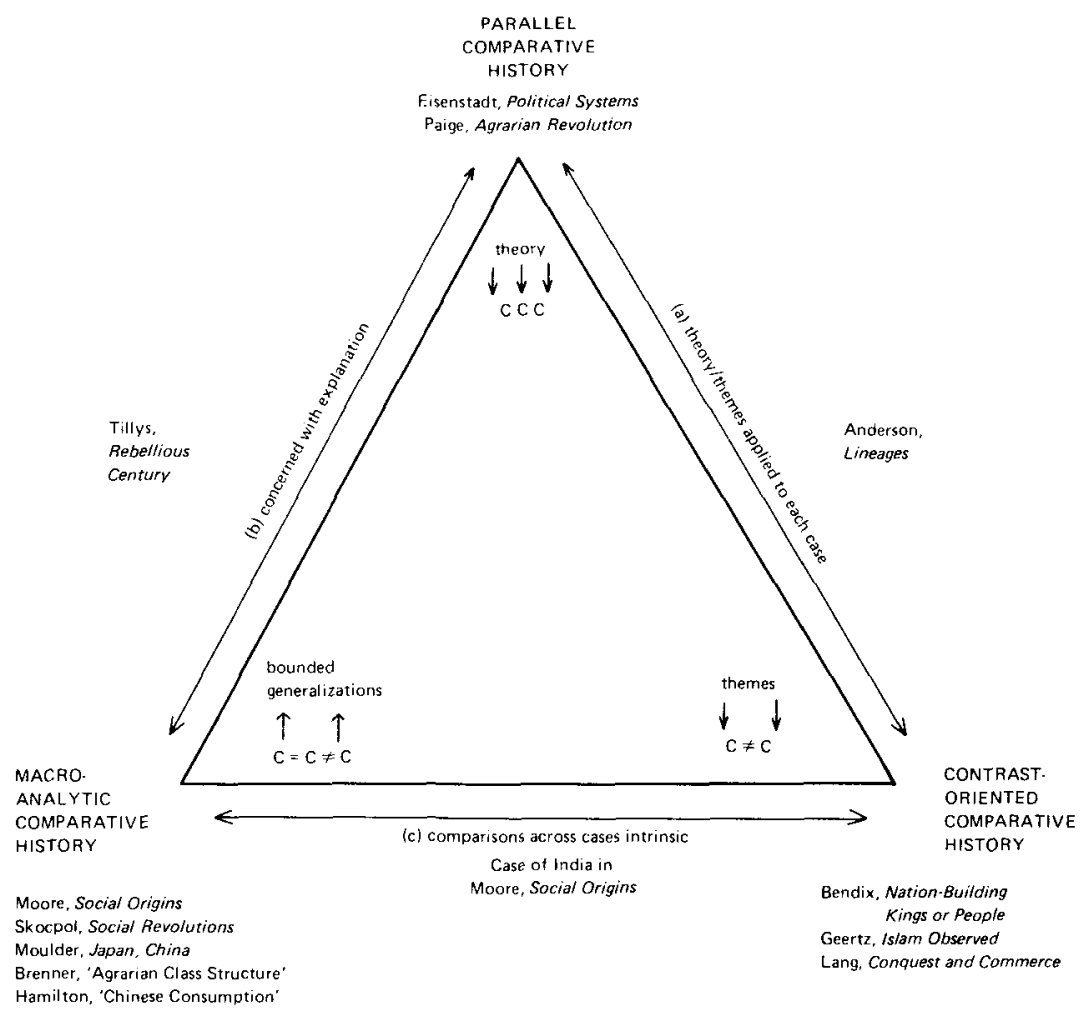

FIGURE 2. The Triangle of Comparative History

the case of the Contrast-oriented approach--are brought to bear on each individual case in the overall comparative-historical investigation. Perry Anderson's Lineages of the Absolutist State sits in the middle of this leg of the triangle because some comparisons in this book are parallel demonstrations of explicit theoretical arguments and other comparisons are contrasts of various cases to one another and to key Marxian concepts. Thus, Parts I and II of Lineages commence with theoretical accounts of why absolutist states emerged in Western and Eastern Europe (respectively). Then case histories follow within each part, with the intention of showing how the theoretically general process worked out specifically in each individual country. Even as the theoretical arguments are being demonstrated through such parallel case accounts, contrasts are also being made between East and West and between and among the individual cases. Moreover, Part III of Lineages and an appended section called "Two Notes" are both devoted primarily to contrasting the non-European cases of Japan, China, and Turkey among themselves and to European history as 
a whole. Anderson argues that Turkey and China contrast to European feudalism, while Japan, despite feudal elements, also contrasts to Europe because it experienced no prior mode of production comparable to Western antiquity. Anderson therefore combines Parallel and Contrastoriented comparative history in complex ways. Yet it is worth noting that there are virtually no elements in Lineages of the Macro-analytic strategy of using controlled comparisons to infer causal generalizations. This fact about Anderson's book is nicely signified by its position on the triangle fully opposite the Macro-analytic corner.

As dimension (b) of the triangle indicates, the Macro-analytic and Parallel types of comparative history share a concern with developing explanations, whether causal generalizations or deductively elaborated theories. This shared concern is an objective absent in the Contrastoriented approach. The Rebellious Century, 1830-1930 sits mid-way on leg (b) of the triangle because this book combines comparisons to test causal hypotheses with parallel demonstrations of an overall theoretical perspective. Rebellious Century examines patterns of collective violence over a century of modern French, German, and Italian history. Within the discussion of each national case, comparisons of regions, times, and various social groups are made to test alternative explanations of how collective violence relates to the expansion of commerce and industry and the rise of national states. This is the distinctively Macro-analytic aspect of Rebellious Century. Across the national cases, however, controlled comparisons are not for the most part attempted. Instead, the Tillys primarily argue that a "solidarity" theory of collective violence best covers all three cases, accounting rather well for the changing overall patterns of collective violence in each national history. Rebellious Century thus combines the more deductive mode of explanation characteristic of Parallel comparative history with the more inductive style of causal inference characteristic of the Macro-analytic approach. And Rebellious Century shows very little concern with using case contrasts to highlight the contextual uniqueness of regions or nations.

Turning to dimension (c) of the triangle, we note that the Contrastoriented and Macro-analytic variants of comparative history share the feature that direct comparisons between or among historical cases are intrinsic to their respective manner of argumentation-intrinsic to highlighting the unique case contexts in the Contrast-oriented type, and intrinsic to making causal inferences in the Macro-analytic type. This shared feature is absent in the Parallel approach, where theory is applied to case histories one by one. Not incidentally, however, it is difficult to find actual works that successfully mix the Macro-analytic and Contrast-oriented logics of comparative history. Although direct comparisons between and among historical cases are common to both approaches, the comparisons 
are by definition used for contradictory purposes: inferring causal generalizations across cases as opposed to highlighting the particular features of individual cases. Obviously it is very difficult to use comparisons involving the same cases to do both of these things at once.

The one instance we have discovered of an explicit attempt to do both at once involves the case of India in Barrington Moore's Social Origins of Dictatorship and Democracy. In many ways, as Moore himself realizes, India does not conform to the pattern exemplified by most of the other nations he analyzes in Social Origins (it was, for example, colonized and had its democratic institutions transmitted from without). And Moore acknowledges that the story of India "constitutes both a challenge to and a check upon the theories advanced in this book as well as others, expecially those theories of democracy that were a response to the very different historical experience of Western Europe and the United States." ${ }^{35}$ Indeed, to a significant degree Moore appears to use the Indian case as a pure contrast, to place limits upon the generality of the major causal arguments of Social Origins. Yet Moore also wants to use India to confirm his causal inferences about the social origins of democracy. ${ }^{36}$ In the end, the Indian case has a somewhat ambiguous place in the overall analysis of Social Origins precisely because Moore uses it for a mixture of both purposes.

Perhaps any "mixed type" work of comparative history will tend to be ambiguous in its message if two (or more) of the major logics are simultaneously applied to the same units of analysis. For not only does Barrington Moore's discussion of India exemplify such ambiguity, so do Parts I and II of Perry Anderson's Lineages of the Absolutist State. In these parts, Anderson attempts to show that his theories of the origins and dynamics of Western Absolutism and Eastern Absolutism apply to the various individual "social formations" of Western as opposed to Eastern Europe. And, simultaneously, Anderson contrasts the individual cases among themselves and to the "pure concepts" of Eastern and Western Absolutism. Often the reader finds it hard to tell whether Anderson means to apply a theoretical generalization or to establish the absolute uniqueness of each case.

The Rebellious Century by the Tillys exemplifies a more successful mixture of two distinct logics of comparative history, probably because each of its logics works at a different level of analysis and refers to a separate set of units. Thus the Parallel logic is applied across nations, while the Macroanalytic logic is used within nations to compare groups, regions, and times. No doubt, when any combination of pairs of the major logics of comparative history is attempted, the relative segregation of the logics within separate parts or levels of analysis within the work as a whole helps to make such a combination less confusing than it would be if the logics were fused

35 Moore, Social Origins, p. 315.

36 See especially ibid., pp. 430-32. 
throughout. In any event, the apparent need for segregation in order to avoid ambiguity helps to reinforce the overall argument of this article concerning the distinct integrity and reality of each major logic of comparative history: the Parallel, the Contrast-oriented, and the Macro-analytic. It is to discussion of these that we now return.

\section{STRENGTHS AND LIMITATIONS OF THE MAJOR TYPES}

The three major logics of comparative history not only have distinctive purposes, patterns of case selection, and modes of exposition, they also have characteristic strengths and limitations. These are worth assessing for each major type in turn.

The Parallel type can be discussed most briefly because the strictly comparative-historical aspect is least important in this approach. As we have seen, the presentation and clarification of a theory is of overriding importance in works of this type. Juxtaposed case histories are useful insofar as they help to spell out the implications of the theory for specific settings, and insofar as they convincingly demonstrate that the theory covers the full range of cases to which it ought (according to its own claims) to apply. When Parallel comparative history is done well, the reader gains a much fuller understanding (than one would from a general theoretical discussion alone) of how key concepts and variables are operationalized and how the theory works "on the ground" to explain actual historical developments. But no matter how many cases are discussed, the historical analyses themselves do not validate the theory. They can only illustrate and clarify it - and, potentially, refine it. This is because, quite obviously, the cases are selected in the first place in terms of the given theory. And the juxtaposed historical trajectories are not used to establish controls, only to show the theory at work again and again.

Since the juxtaposition of multiple case histories cannot actually strengthen the validation of their theories, practitioners of Parallel comparative history run the risk of being overly repetitive without commensurate methodological gain. Arguably, both Eisenstadt at places in The Political Systems of Empires and the Tillys in The Rebellious Century fall into this trap. The difficulty of fruitless repetition is particularly striking in The Rebellious Century, where exactly the same basic theoretical argument is presented in the introduction and conclusion of the book, in addition to being developed three times over in the lengthy core chapters on France, Germany, and Italy. Although the historical cases certainly have intrinsic interest, nothing of any theoretical significance would have been lost had The Rebellious Century discussed only one national case rather than three.

Not all works of Parallel comparative history end up seeming repetitious, however. Jeffery Paige's Agrarian Revolution cleverly avoids this problem. Because of the complexity of his theoretical argument, in which 
he predicts several possible historical outcomes, Paige can use the individual case analyses to illustrate different major parts of the overall theoretical argument. Readers are kept interested with varied fare, even as the logical requisites of Parallel comparative history are fulfilled. ${ }^{37}$

Practitioners of Contrast-oriented comparative history stand squarely in the middle between the characteristic disciplinary concerns of social scientists and historians. These comparativists actually care about general issues that cross-cut particular times and places. Indeed, this is what motivates them to do comparative studies rather than single-case historical accounts. Yet Contrast-oriented comparative historians are also profoundly skeptical of received social-scientific theories and uncertain about the prospects for developing any valid macro-level explanatory generalizations at all. Thus they pursue comparative history within the confines of a kind of "self-denying ordinance" against endeavors to develop new explanations. This self-conscious refusal to use comparative history to explain is at once the chief strength and the greatest weakness of the Contrast-oriented approach. It is a strength because the refusal to develop explanations allows Contrast-oriented comparativists to present unbroken accounts of the unique histories of different societies. Historical cases may be used to point out the limits of received general theories, but for the most part the focus is not on theories or hypotheses or explanatory problems. Rather it is on the cases themselves and the contrasts between and among them that underline the uniqueness of each. The determined exploration of the unique features of each case leads inevitably toward a kind of descriptive holism. Thus the studies done by Contrast-oriented comparative historians do much to bring out the rich details of diverse societies and cultures and to show how the different spheres of each society and culture inextricably interrelate. Furthermore, Contrast-oriented comparativists take chronology very seriously, emphasizing how sociocultural experiences exhibit continuity over time. It is hardly incidental that Contrast-oriented studies almost always include lengthy, unified case accounts, with events kept strictly in chronological order. Indeed, quite often an unmistakable "genetic determinism"--a tendency to say that earlier, and ultimately the earliest, happenings determine what comes later-creeps into Contrast-

\footnotetext{
${ }^{37}$ Another work that uses Parallel comparative history in a non-repetitious and unusually interesting way is Poor People's Movements (New York: Pantheon, 1977) by Frances Fox Piven and Richard Cloward. The purpose of this book is to present a theory of the emergence and fate of insurgent movements by non-privileged groups in U.S. society. After the theory is outlined, four cases are presented to illustrate it. Each represents a particular protest movement and a specific "slice in time" from U.S. history between 1930 and the early 1970 s. Taken together, the cases add up not only to four separate applications of Piven and Cloward's theoretical perspective on protest movements, but also to a coherent account of the course of U.S. politics since the 1930 s, viewed from the bottom up. Piven and Cloward thus uniquely fuse the juxtaposition of cases characteristic of Parallel comparative history with the holism and drama characteristic of an in-depth exploration of a single national experience.
} 
oriented presentations. Despite their considerable differences in subject matter and implicit theoretical frameworks, Clifford Geertz's Islam Observed, James Lang's Conquest and Commerce, Reinhard Bendix's Kings or People, and Perry Anderson's Lineages of the Absolutist State all exhibit this genetic-determinist proclivity.

Of course the price paid in Contrast-oriented comparative histories is that descriptive holism precludes the development of explanatory arguments, even when these are implicitly present, crying to be drawn out of the comparative-historical materials. Independent and dependent variables are never explicitly distinguished, and the chronological account, "telling the story," is allowed to suffice as the mode of conveying understanding of what happened and why. Worse yet, most (if not all) works of Contrastoriented comparative history actually smuggle implicit theoretical explanations into their case accounts. Usually this happens through the device of posing common themes or questions to provide the framework for the case accounts and comparisons. In the books of Reinhard Bendix, for example, it is abundantly apparent to any theoretically astute reader that a kind of idealistic Weberian explanation of "modernizing" transformations of political authority structures is being proffered in the introductory sections and throughout the case histories. Bendix makes quasi-explanatory arguments along these lines, and he selects what happenings and aspects of social life to include, or not, in his case histories in a manner appropriate to his implicit theoretical perspective. In a way, there is nothing surprising in this, for it is difficult to see how anyone could survey thousands of years of world history without theoretical guidance. But, of course, the irony is that, like any good Contrast-oriented comparative historian, Bendix disclaims explicit theoretical or explanatory objectives. He presents his themes and concepts as if they were self-evident truths, or else neutral tools, when in fact they imply explanatory hypotheses whose validity could be challenged. Indeed, other comparativists have covered exactly the same ground as Bendix using very different theories or themes.

In short, Contrast-oriented comparative history offers the advantages of holistic, rich descriptions and full, chronological case accounts. Limits to the applicability of received general theories can be dramatically revealed through this approach. But the Contrast-oriented approach can also be theoretically very misleading. For virtually any themes can be brought to bear upon the case materials without being put to any explicit test and without being openly identified as a proto-theory.

Macro-analytic comparative history has the considerable virtue of being the only way to attempt to validate (and invalidate) causal hypotheses about macro-phenomena of which there are intrinsically only limited numbers of cases. The problem is that perfectly controlled comparisons are never really feasible. Societies cannot be broken apart at will into analyti- 
cally manipulable variables; and history rarely, if ever, provides exactly the cases needed for controlled comparisons. Indeed, John Stuart Mill himself despaired of the possibility of effectively applying the analytic methods he discussed to sociohistorical phenomena. ${ }^{38}$ And as we have seen, scholars such as Reinhard Bendix have concluded that given the difficulties of doing rigorous causal analysis at the macro level, the attempt should not be made at all.

But complete retreat in the face of the difficulties is surely unnecessary. Even if the validity of macro-level causal hypotheses can never be perfectly established, highly suggestive studies can often be successfully completed. Moreover, macro-causal analysis remains a powerful tool for criticizing and invalidating mistaken theories. As the articles by Robert Brenner and Gary Hamilton clearly show, it is often possible to demonstrate through elementary comparative-historical analysis that widely accepted explanations simply cannot account for variations across times and places. Such critical use of comparative-historical analysis in turn prods social scientists to look for more promising explanatory hypotheses. And insofar as carefully delineated explanatory problems are tackled one by one, considerable progress can usually be made in setting up comparisons across time and/or space to test alternative hypotheses about each problem.

The great comparative historian Marc Bloch once made a statement that could be taken as a maxim for Macro-analytic comparativists, especially in opposition to their Contrast-oriented counterparts: "The unity of place is only disorder," Bloch declared. "Only the unity of problem makes a. center." 39 When they ply their trade most thoroughly, Macro-analytic comparative historians take this maxim very seriously. Cases are selected and case materials are manipulated according to the logic of the causal hypotheses being presented and tested. The temptation to narrate unbroken sequences of events about each time and place is resisted when this proves unnecessary for dealing with the explanatory problem at hand. Indeed, from the point of view of Contrast-oriented comparativists (or of traditional historians), Macro-analytic comparative history done well may seem very unaesthetic because in it the unities of time and place are broken. But of course the breaking apart of temporal and geographic unities is exactly what is needed if explanatory problems are to be solved. Unlike Contrast-oriented comparative history, it is arguable that Macro-analytic comparative history is better done in article format rather than in books. For it may be easier in articles to highlight causal arguments, to move freely

${ }^{38}$ Mill, "Two Methods," in Etzioni and Du Bow, eds., Comparative Perspectives, pp. 210-13.

${ }^{39}$ Marc Bloch, "Une Étude Régionale: Géographie ou Histoire?" Annales d'Histoire Economique et Sociale 6 (January 1934), p. 81 (our translation). 
back and forth across times and places, and to avoid the temptations of presenting lengthy descriptive chronologies for their own sake. ${ }^{40}$ Certainly when Macro-analysts do write books, they face the challenge of integrating descriptive accounts with causal arguments. Historical trajectories cannot simply be juxtaposed and contrasted; controlled comparisons (the best approximations possible) must be explicitly presented.

Macro-analytic comparative history has been-and will continue to be-done skillfully. Even so, it is important to recognize that this method offers no automatic or complete solutions to macrosocial explanatory problems. As suggested by the juxtaposition of Marion Levy, Jr.'s study of the "Contrasting Factors in the Modernization of China and Japan"4l to Frances Moulder's recent (1977) Japan, China and the Modern World Economy, it is quite possible for investigators of differing theoretical proclivities to use the same comparative-historical logic to ask about the causes of what is basically the same phenomenon occurring in the same cases, and yet come up with contradictory answers. In both of these studies, the Method of Difference is skillfully employed. The point is that the method itself is no substitute for theory, and cannot in itself guarantee reliable and valid conclusions.

Moreover, even when the conclusions of a Macro-analytic comparative study do seem perfectly sound, there are still unavoidable difficulties about how to generalize the explanation beyond the historical cases actually included in the given study. Can Barrington Moore's arguments be applied to the political development of countries other than the eight actually covered by Social Origins of Dictatorship and Democracy? Can Theda Skocpol's arguments about social revolutions in France, Russia, and China be extended to other cases (and failures) of social-revolutionary transformations? The answer is that, because they are largely inductively established, comparative-historical causal arguments cannot be readily generalized beyond the cases actually discussed. In the preface to Social Origins, Barrington Moore likens the generalizations his study establishes to "a large-scale map of an extended terrain, such as an airplane pilot might use in crossing a continent." 42 This is an appropriate metaphor. And the reflection it inspires in this context is that no matter how good the map were of, say, North America, the pilot could not use the same map to fly over other continents.

Providing links among valid causal generalizations about different sets

${ }^{40}$ For examples see the articles cited in note 32 and Theda Skocpol, "France, Russia, China: A Structural Analysis of Social Revolutions," Comparative Studies in Society and History 18:2 (April 1976): 175-210.

${ }^{4 !}$ Marion J. Levy, Jr., "Contrasting Factors in the Modernization of China and Japan," in Simon Kuznets, Wilbert E. Moore, and Joseph J. Spengler, eds., Economic Growth: Brazil, India, and Japan (Durham, N.C.: Duke University Press, 1955): pp. 496-536.

42 Moore, Social Origins, p. xiv. 
of times and places is, ideally, the task of truly "general" theories. Macroanalytic studies cannot completely substitute for general theory-building. Nevertheless, general theories about societal dynamics and epochal transformations are best developed only in close relationship with the findings of Macro-analytic comparative histories. Would-be "universal" theories, developed at high levels of abstraction without any reference to comparative-historical patterns, can end up not explaining any causal connections in history very well. But if general theories can be developed in tandem with Macro-analytic investigations, then we should be able, over time, to improve the depth and, especially, the scope of our explanations of societal structures and their historical transformations.

\section{CONCLUSION}

In sum, "comparative history" is not a single, homogeneous logic of macrosocial inquiry. Rather it encompasses at least three major logics with distinct purposes, characteristics, strengths, and limitations. Normally, a single investigator pursuing a given comparative-historical study will want and need to use just one of these major logics, or, at most, a carefully combined pair. Comparative historical studies seem to work best when they are done primarily according to one logic or another.

Even so, at the level of the macrosocial enterprise as a whole - the overall quest for understandings about societal orders and social change- the Parallel, Contrast-oriented, and Macro-analytic approaches together form a complementary system. For each type at its own distinctive limits tends to suggest needs and possibilities for studies of the other types. This especially happens, we would argue, in the cycle suggested by Figure 3 .

Thus Parallel comparative history tends to call forth Contrast-oriented arguments when the need develops to set limits to the scope or claims of an overly generalized social-scientific theory. Contrast-oriented comparative history may give rise to Macro-analytic arguments when juxtapositions of historical trajectories begin to suggest testable causal hypotheses. Finally, too, Macro-analytic comparative history can create a demand for the kind of general theorizing that precedes the construction of a Parallel comparative analysis. This happens when there develops an interest in generalizing causal hypotheses beyond a given set of historical cases, in order to encompass all - or a broader range - of cases exemplifying the phenomenon to be explained. If the new theoretical claims then seem to overreach themselves, the cycle is very likely to begin again.

The arguments of this article about major types of comparative history will, we hope, contribute in several ways to the further development of historically oriented macrosocial research. For one thing, although methodological "recipes" are neither possible nor desirable, future comparative-historical research can surely benefit from a clearer awareness on the 


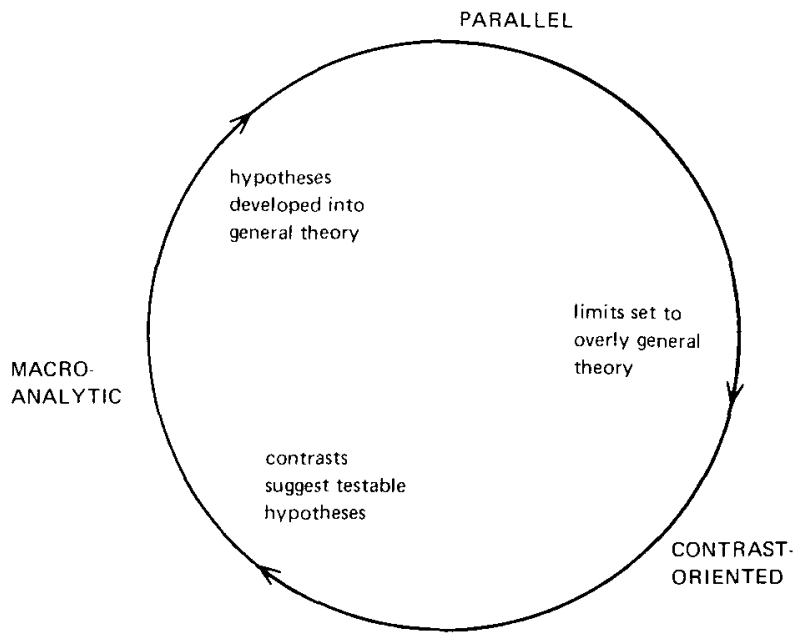

Figure 3. A Cycle of Transitions

part of investigators of the methodological alternatives that have proved fruitful in the past. In addition, the informed appreciation of such research should be enhanced if relevant audiences understand the distinct purposes and characteristics of the major logics of comparative history. For works of different types can then be recognized for what they are and judged in appropriate terms. Finally, and perhaps most important, the time has come for debates to flourish about the practical methods for mediating between theories and historical evidence that actually have been, or might be, used by macroscopically-oriented historical sociologists and social historians. Disputes about theoretical paradigms and philosophies of social inquiry cannot substitute for such properly methodological reflections; neither can discussions solely focused upon quantitative techniques of data analysis. Thus, even if this essay on the uses of comparative history does nothing more than arouse interested skepticism and provoke thoughtful counterarguments, it will nevertheless have achieved its most basic aim - to encourage methodological reflection by all those who practice or appreciate historically-oriented macrosocial inquiry. 